\title{
REFORMA GERAL DA RETOMADORA DE MINÉRIO*
}

\author{
Everton Azola de Mattos ${ }^{1}$ \\ Guilherme Reis Pereira ${ }^{2}$ \\ Joenilso Ribeiro de Freitas ${ }^{3}$ \\ José Ricardo Baltazar \\ Marcelo Ito $^{5}$
}

\section{Resumo}

A Retomadora de Minério 342-RE-001 da Anglo American é um equipamento fundamental para a homogeneização do minério, porém este equipamento apresentava problemas de performance operacional desde início da operação da Planta Industrial de Barro Alto. Em agosto de 2015, as equipes de Engenharia e Manutenção realizaram um levantamento de todas as intervenções feitas no equipamento desde o início da operação em 2012, classificando estas intervenções em seis grupos, utilizando as ferramentas da metodologia Lean Six Sigma. Desta forma, foi possível realizar o Retrofit da roda de caçambas, manutenção geral nos rastelos, trucks e na lógica de automação que eram os sistemas que mais impactavam na estabilidade e disponibilidade física do equipamento.

Palavras-chave: Retomadora de minério; Disponibilidade física; Roda de caçambas; Lean six sigma.

\section{Abstract}

\section{GENERAL REFORM AT ORE RECLAIMER}

The Reclaimer ore 342-RE-001 Anglo American is a key equipment for the ore homogenization, but this equipment has operational performance problems since the beginning of the Barro Alto Industrial plant operation. In August 2015, the team of Engineering and Maintenance conducted a survey of all the interventions made in the equipment since the beginning of operation, classifying these interventions in 6 groups, using the tools of Lean Six Sigma methodology. Thus, it was possible to perform the redesign of the bucket wheel and also general maintenance on scrapers, trucks, and automation which were the systems that most impacted the stability and availability of equipment.

Keywords: Ore reclaimer; Availability; Buckets wheel; Lean six sigma.

1 Engenharia Elétrica e Eletrônica, Pós-graduado, Coordenador de Instrumentação e Automação, Manutenção, Anglo American, Barro Alto, Goiás, Brasil.

2 Engenharia Mecânica, Bacharel, Engenheiro de Manutenção, Manutenção, Anglo American, Barro Alto, Goiás, Brasil.

3 Administração de empresas e Técnico em Mecânica, Bacharel, Supervisor de Manutenção, Manutenção, Anglo American, Barro Alto, Goiás, Brasil.

4 Engenharia Mecânica, Pós-graduado, Gerente de Manutenção, Manutenção, Anglo American, Barro Alto, Goiás, Brasil.

5 Engenharia Mecânica, Bacharel, Engenheiro de Projetos, Engenharia de Manutenção, Anglo American, Barro Alto, Goiás, Brasil. 


\section{INTRODUÇÃO}

A Anglo American durante o ano de 2015 realizou projeto multidisciplinar para a otimização do ativo 342-RE-001, que se trata de uma retomadora de minério tipo ponte, fabricação Bardella S/A.

A retomadora de minério apresenta problemas de performance operacional desde o start up da planta industrial de Barro Alto, com frequentes quebras e paradas da linha de produção.

A Reforma Geral da Retomadora de Minério teve como objetivo realizar a reengenharia de componentes do equipamento que apresentavam problemas de performance operacional.

Para definição da estratégia de solução foi realizada uma análise profunda dos principais tipos de problemas ou intervenções da equipe de Manutenção Industrial utilizando a metodologia Lean Six Sigma.

\section{MATERIAIS E MÉTODOS}

Para definição da estratégia de manutenção foi realizada análise profunda dos principais tipos de intervenções da equipe da manutenção. As frequentes manutenções afetavam diretamente a disponibilidade física do equipamento, a qual deve ser superior a $97,9 \%$.

Conforme pode ser visto no Gráfico 1, historicamente, a disponibilidade física do equipamento não atingiu a meta de $97,9 \%$ desde o início da operação, apesar de todas as melhorias realizadas.

Disponibilidade Física - Análise Histórica

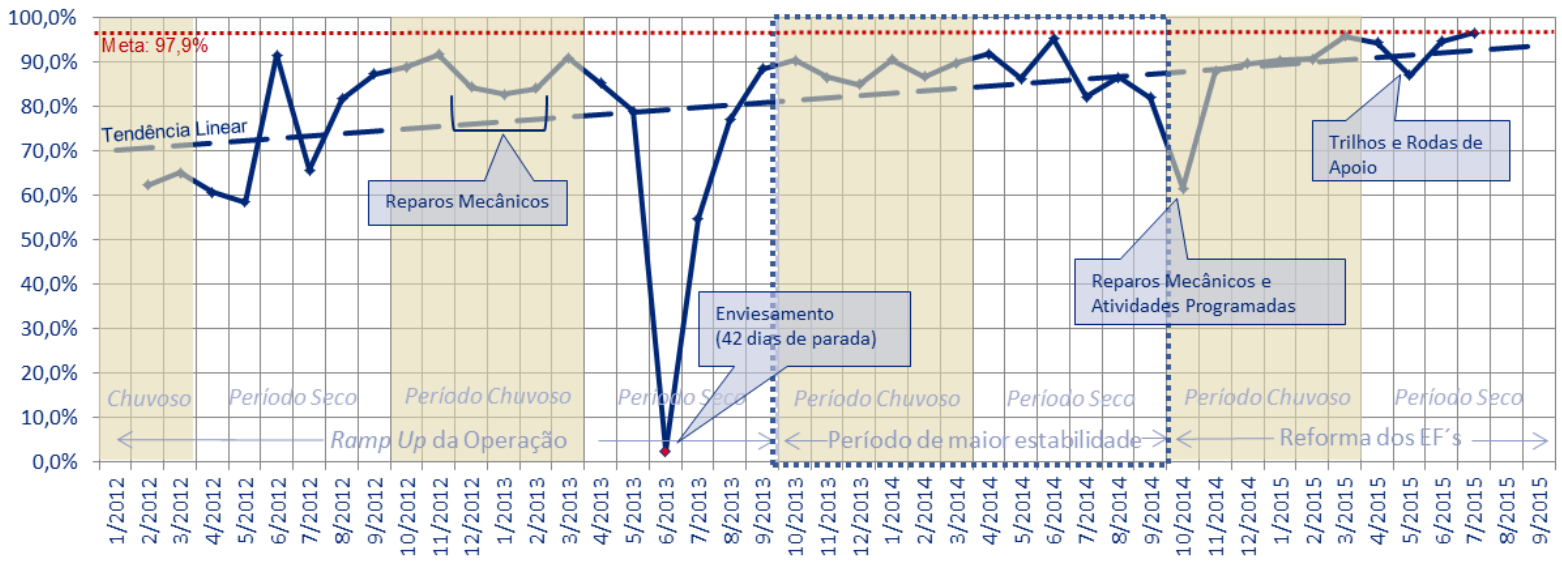

Gráfico 1: Disponibilidade Física - Retomadora 342-RE-001.

Para definição das atividades a serem realizadas no equipamento foi realizado um levantamento detalhado das 2030 Ordens de Serviço destinadas ao equipamento 342-RE-001, que foram originadas desde o início da operação da planta industrial em janeiro de 2012 até agosto de 2015, conforme disponível no ERP. 
INTERVENÇÕES - MECPC - Q1/2011 até Q3/2015

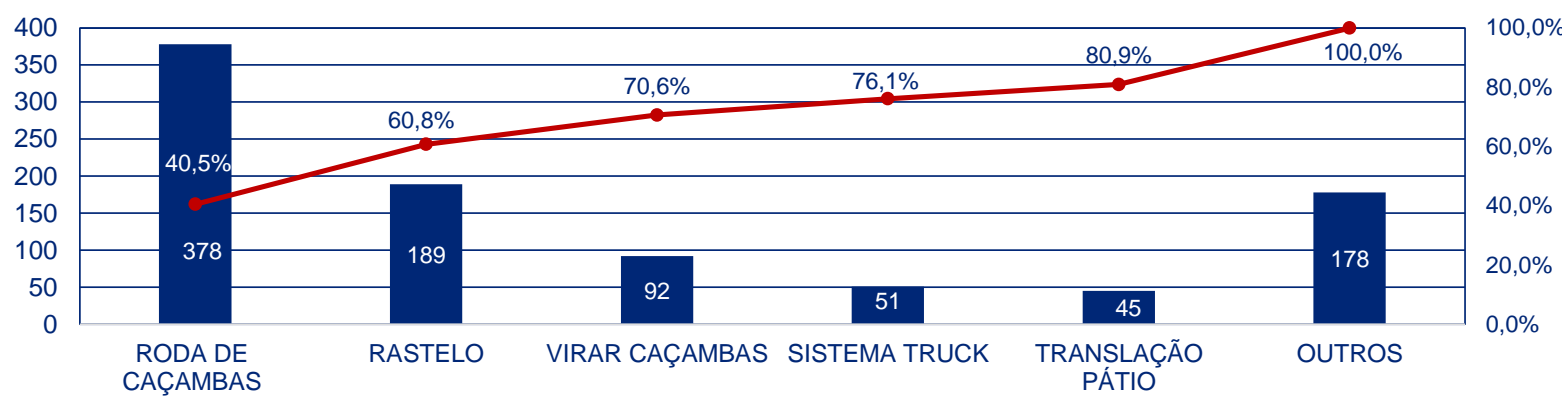

Gráfico 2: Subsistemas da Retomadora com maior número de intervenções.

As ordens de serviço foram classificadas em seis grupos, conforme pode ser visto no Gráfico 2, sendo o mais recorrente a realização de atividades na Roda de Caçambas, seguido por atividades nos Rastelos e nos Trucks. A atividade de Virar Caçambas é uma necessidade operacional, a qual não impacta na DF do equipamento.

Em maio de 2013 houve um evento de enviesamento do equipamento, que trouxe como consequência a ovalização da estrutura da roda de caçambas em aproximadamente $25 \mathrm{~mm}$ (máximo permitido por norma: $8 \mathrm{~mm}$ ).

Além disso, verificou-se nos históricos da operação que existia uma aderência de minério nas caçambas, de maneira que, o material retomado não seguia o fluxo previsto, e consequentemente 0 equipamento não atingia a taxa horária (toneladas/hora) de minério retomado.

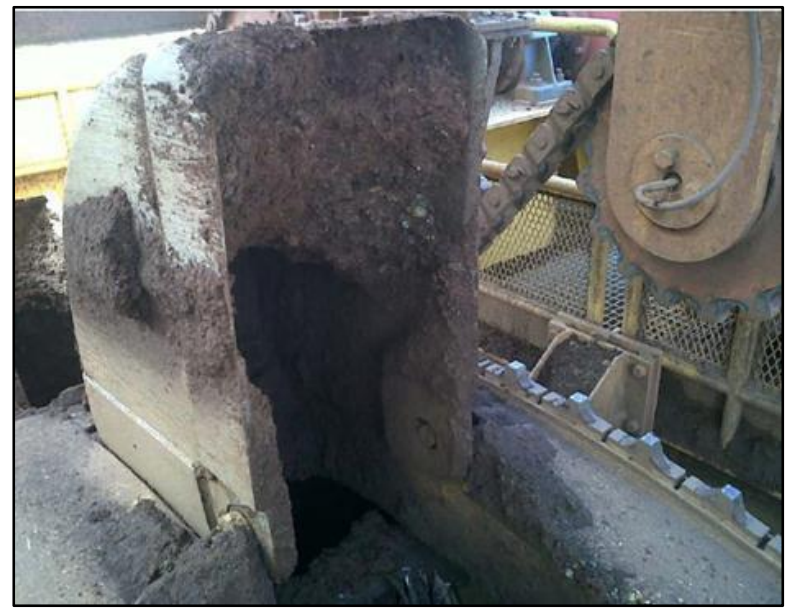

Figura 1: Minério aderido a caçamba.

No escopo da reforma geral decidiu-se pela reengenharia da Roda de Caçambas, por ser o maior número de intervenções, pelo problema da ovalização, e também, pela baixa performance operacional devida a aderência do minério. Esta atividade foi executada sob gestão da equipe de Engenharia de Manutenção.

Para os outros grupos com grande incidência de intervenções (Rastelos e Trucks) foi decidido a realização de reformas e substituições dos componentes que apresentam desgastes, sob gestão da equipe de Manutenção.

Decidiu-se também realizar melhorias no sistema de controle de avanço do carro móvel sobre a viga principal do equipamento, pois a velocidade de deslocamento setada tinha perfil constante, gerando grande variação na taxa instantânea de retomada. Esta melhoria foi realizada sob gestão da equipe de Manutenção de Instrumentação e Automação. 


\section{RETROFIT DA RODA DE CAÇAMBAS - ENGENHARIA CONCEITUAL}

Para a reengenharia da Roda de Caçambas foi realizado um estudo conceitual, em parceria com a Bardella - fabricante da retomadora - a empresa canadense EMSTECK, onde se estudou detalhadamente os problemas existentes na roda de caçambas, como por exemplo: a ovalização, o dimensionamento estrutural e a aderência do minério, objetivando atingir a taxa horária do equipamento que é de $508 \mathrm{t} / \mathrm{h}$.

Foram realizados modelos computacionais utilizando os parâmetros do minério (adesão, coesão, umidade), a fim de se obter o num novo design das caçambas.

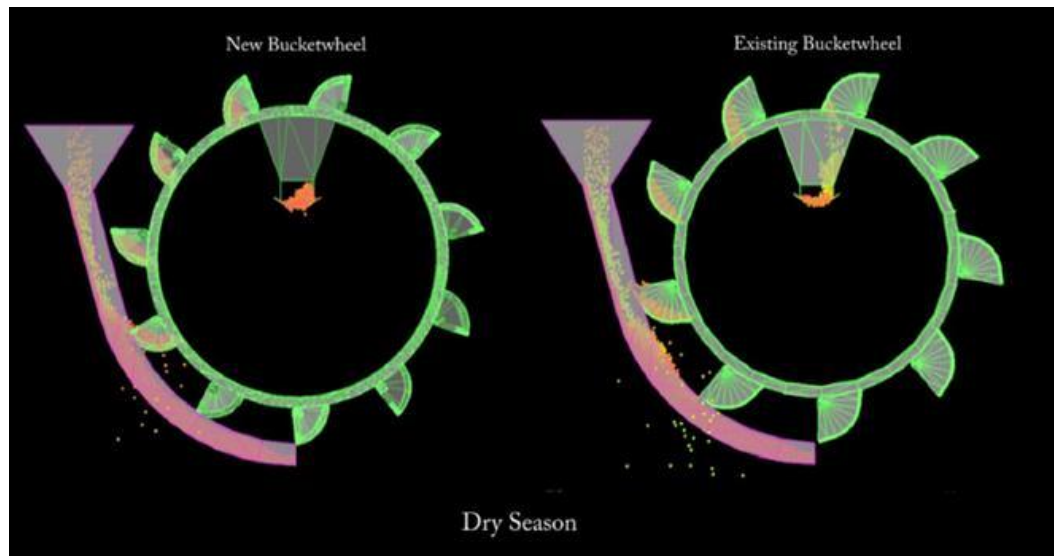

Figura 2: Modelo Computacional para definição no novo layout da roda de caçambas.

No melhor resultado obtido houve incremento de $200 \mathrm{~mm}$ no raio da roda, incremento de $200 \mathrm{~mm}$ na largura e alteração no número de caçambas, que passou de 9 para 11 unidades, e ainda, outros pontos de melhorias nas rodas de apoio/encosto e no engrenamento da corrente de acionamento. Entretanto, não houve alteração do raio de corte, ou seja, a elevação de corte no piso do pátio foi preservada.

\section{ENGENHARIA DETALHADA E FABRICAÇÃO DA NOVA RODA DE CAÇAMBAS}

$\mathrm{Na}$ etapa seguinte teve a engenharia detalhada e fabricação da nova roda de caçambas, para a execução foi contratada a Bardella S/A.

Durante todo o processo de fabricação foram realizadas visitas de Diligenciamento e Inspeções na fábrica da Bardella em Sorocaba e em Guarulhos.

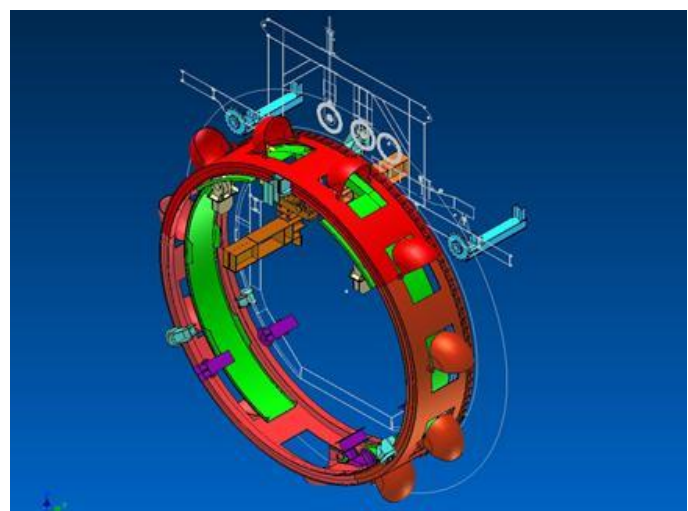

Figura 3: Vista 3D da Nova Roda de Caçambas. 



Figura 4: Fabricação da Nova Roda de Caçambas.

Figura 5: Peças prontas para Expedição.

\section{REFORMA GERAL DA RETOMADORA MINÉRIO}

No dia 07 de Dezembro de 2015, a Retomadora de Minério foi posicionada no centro do pátio de homogeneização para a substituição da roda de caçambas, e também, para atividades de manutenção nos trucks e nos rastelos. A duração prevista para as atividades era de 15 dias para a execução e mais 7 dias de comissionamento.

\subsection{Substituição da Roda de Caçambas}

A seguir é possível encontrar o registro fotográfico apresentando as estruturas da roda de caçambas antiga, que foram removidas, e as novas estruturas montadas no equipamento.

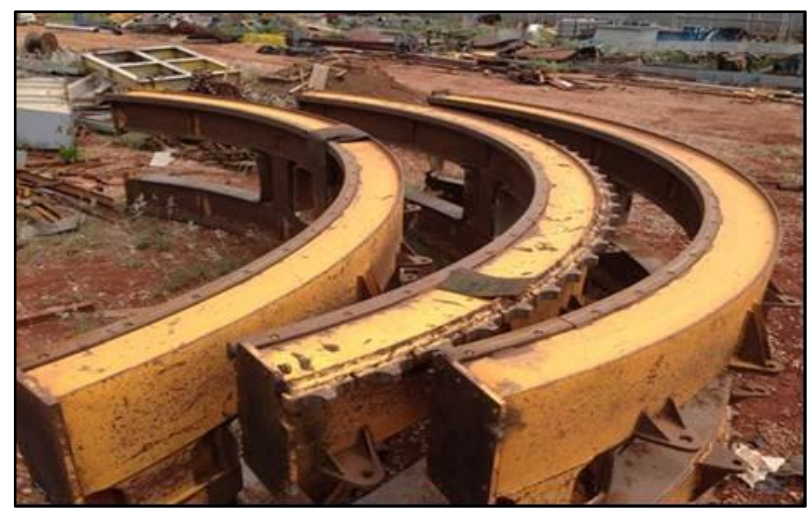

Figura 6: Segmentos da Roda Removidos

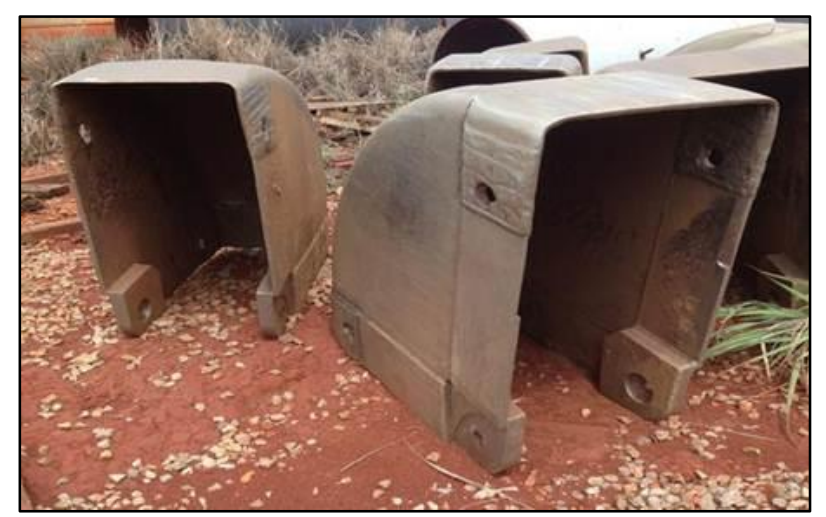

Figura 8: Caçambas Antigas.

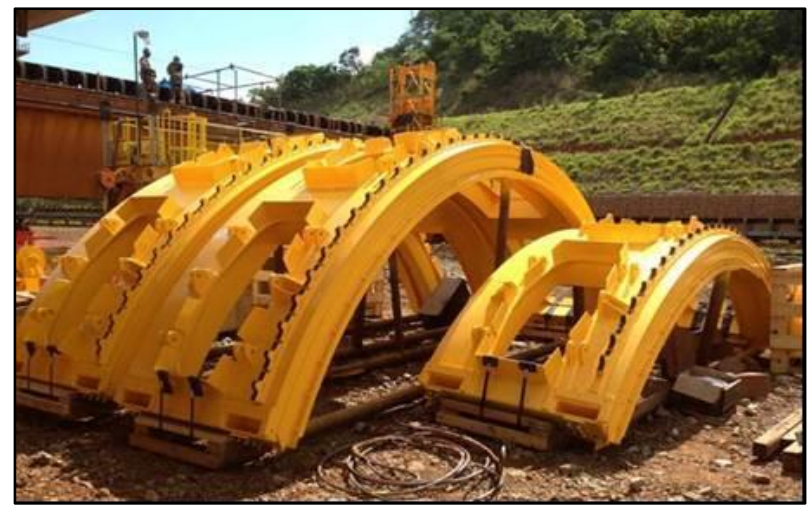

Figura 7: Segmentos da Nova Roda de Caçambas

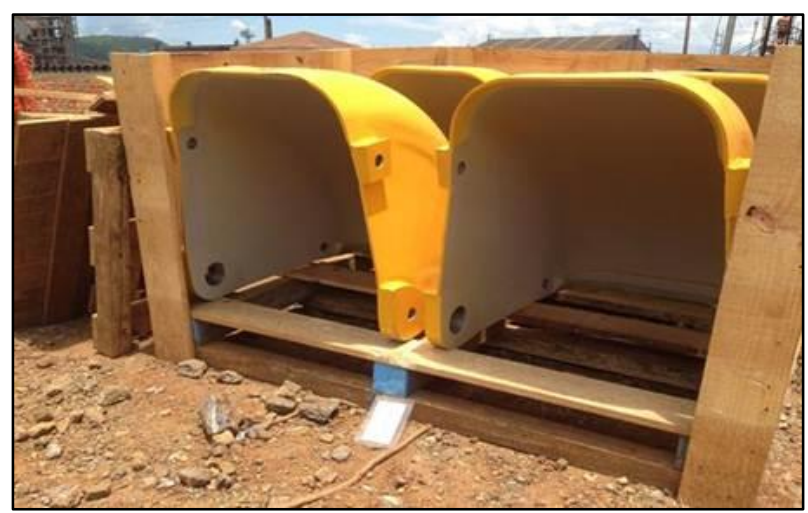

Figura 9: Novas Caçambas. Novo design. 


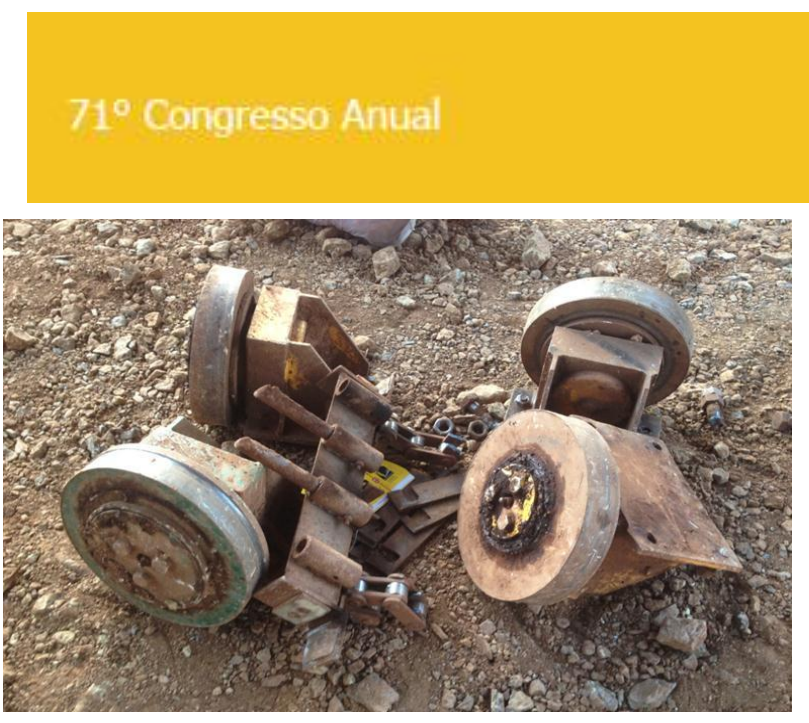

Figura 10: Rodas de Apoio Antigas.

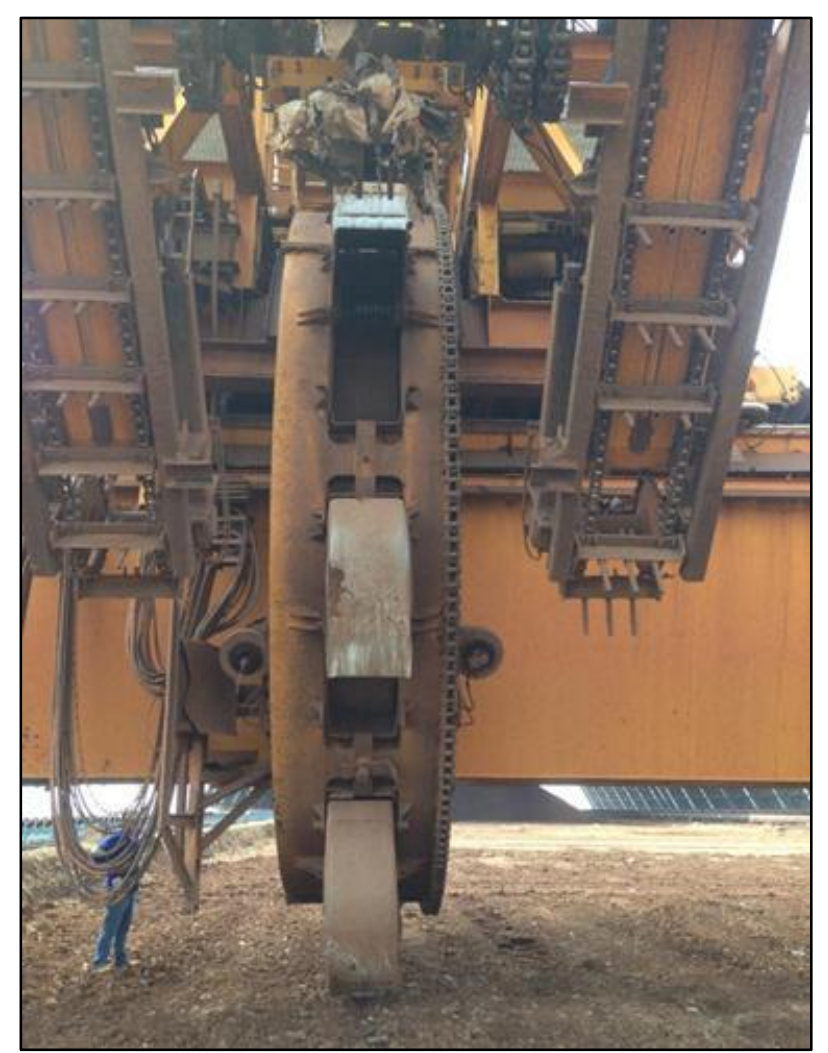

Figura 12: Roda de Caçambas Removida e Rastelos.

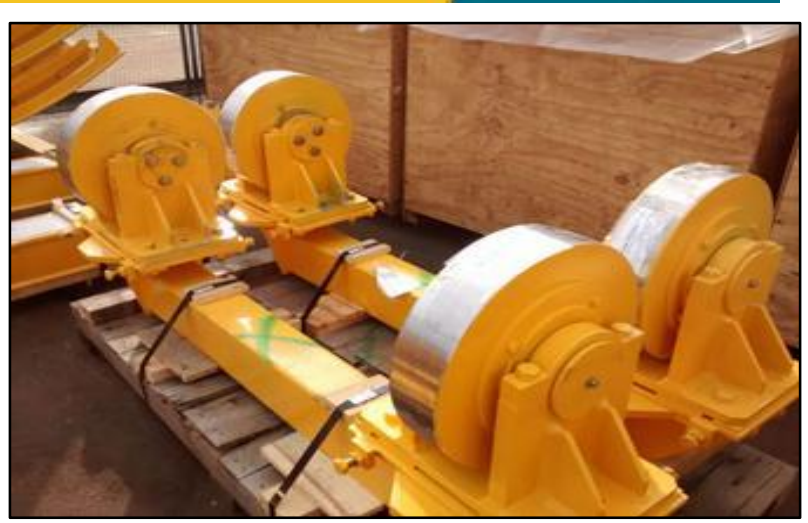

Figura 11: Novas Rodas de Apoio.

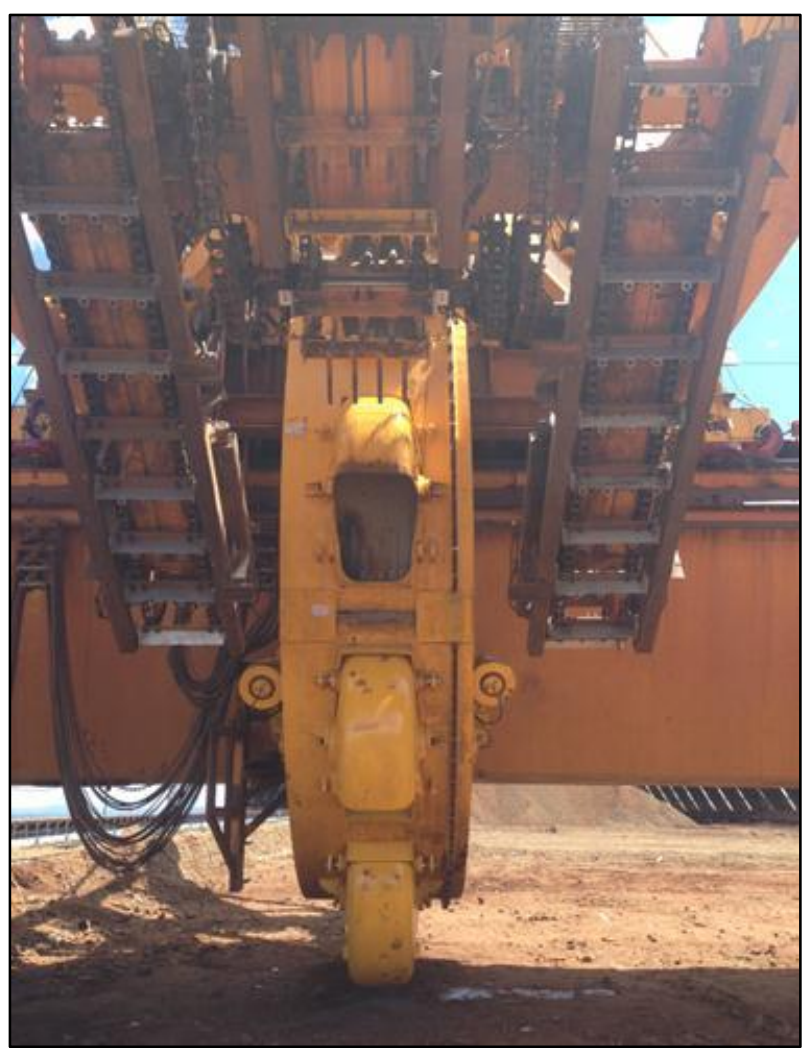

Figura 13: Nova Roda de Caçambas Montada e Rastelos.

\subsection{Reforma Completa dos Rastelos}

Os rastelos são componentes essenciais para retomadoras do tipo ponte. Eles são componentes responsáveis para homogeneização do material, visto que essa é uma das principais características observadas na escolha dessa classe de retomadoras. Esse equipamento possui dois conjuntos de rastelos, sendo um voltado para o lado norte e outro para o lado sul. Cada conjunto dois rastelos menores ( 3,7 metros) e um maior (15 metros).

\subsubsection{Troca das correntes e pentes do rastelo}

Foram trocadas todas as correntes de todos os rastelos. O Alongamento máximo da corrente do rastelo admissível (3\%) já havia sido atingido. O tempo prolongado de 
parada do equipamento para a troca da roda de caçamba foi oportuno para a realização desta intervenção.

\subsubsection{Troca dos guias das correntes do rastelo}

A corrente do rastelo corre sobre trilhos feitos em Hardox 400. A intervenção é extensa por é necessária a remoção completa das correntes e os trilhos são soldados na estrutura. O papel fundamental dos trilhos é proteger a estrutura da máquina contra o atrito com as correntes dos rastelos.

\subsubsection{Troca dos palitos do rastelo}

Os palitos são montados nos pentes e são responsáveis por escarear a pilha de minério, reduzindo o esforço de retomada e homogeneizar o material, pelo arraste do material para a parte inferior da pilha onde as caçambas coletam o material.

O desgaste desses palitos comprometem sua penetração na pilha e consequentemente o escareamento do material. Além do natural comprometimento da homogeneização, há também a redução do tempo de vida de diversos componentes mecânicos da roda de caçamba, devido ao esforço adicional.

\subsection{Manutenção dos trucks e alinhamento do carro}

Durante a troca da roda de caçamba foi feita a reforma dos trucks de translação. Conforme pode ser observado na Figura 15, o carro apresentava desalinhamento acentuado no sentido norte-sul, favorecendo o aumento no esforço das rodas guias do trucks, causando quebra dos rolamentos destas.

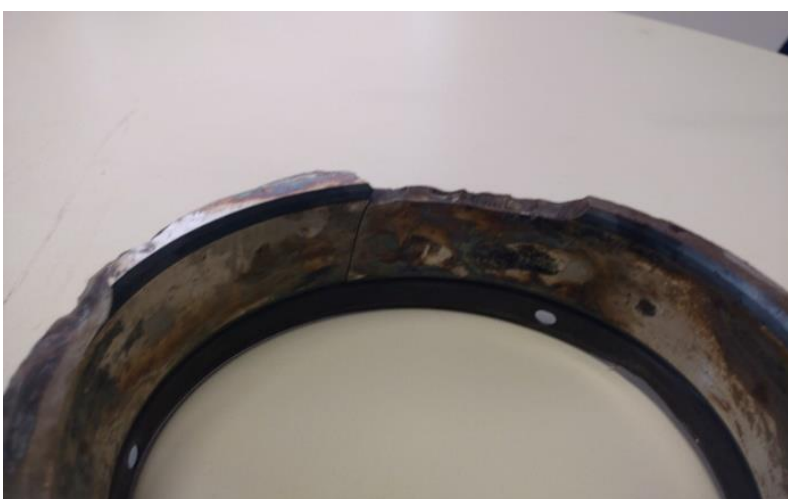

Figura 14: Quebra na pista externa do rolamento.

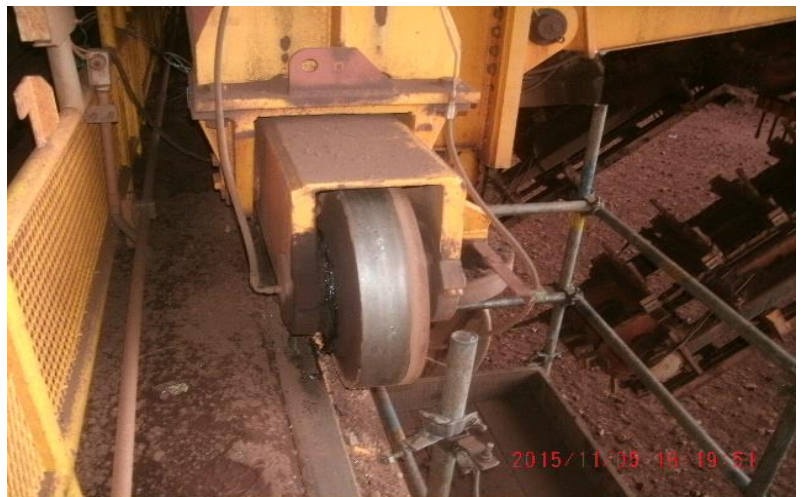

Figura 15: Descarrilamento do equipamento.

Após um esforço prolongado devido ao desalinhamento e a quebra do rolamento, o carro do equipamento descarrilhava. Eventos como este, causam um tempo de parada prolongado do equipamento (aproximadamente 12 horas), mesmo com todo sobressalente necessário disponível. 


\section{MELHORIAS DE CONTROLE E AUTOMAÇÃO}

Foi implementada uma melhoria na lógica de avanço do carro móvel sobre a viga principal da retomadora.

O projeto original previa que a velocidade de translação do carro móvel deveria ser determinada pela corrente de acionamento da motorização, sendo o valor da corrente fixado em $90 \%$ da corrente nominal.

$\mathrm{O}$ avanço do equipamento sobre a pilha de minério se dava de acordo com o totalizador da balança integradora embarcada.

Ao lado do Gráfico 3, antes da melhoria, é possível encontrar a descrição de cada curva, sendo a primeira curva de cima para baixo a indicação instantânea da balança integradora, com range no eixo das ordenadas variando de 0 a $1200 \mathrm{t} / \mathrm{h}$; a segunda curva o set point da corrente da motorização em $90 \%$ da nominal; a terceira representa a posição do carro móvel sobre a viga, sendo a posição zero uma extremidade do equipamento e a posição $40 \mathrm{~m}$ a outra extremidade; a quarta e última curva representa o avanço do equipamento da pilha de minério.

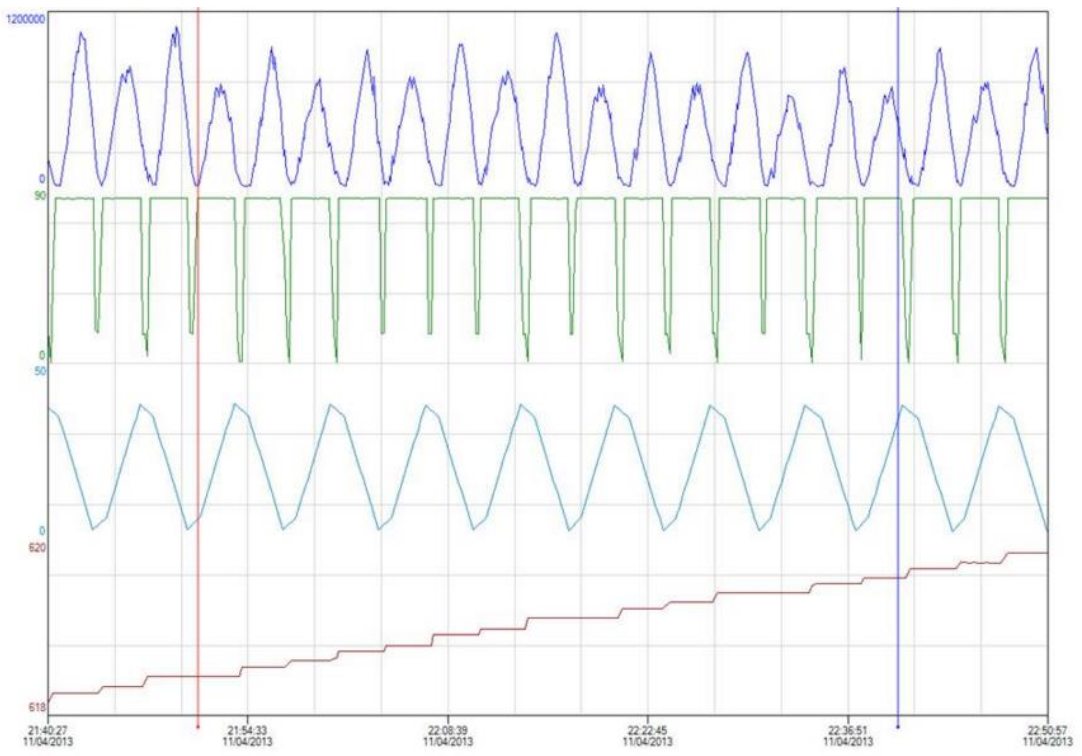

Gráfico 3: Controle de avanço - Antes da Melhoria
- Taxa instantânea da balança integradora embarcada.

- Set point da corrente da motorização do carro móvel.

- Posição do carro móvel sobre a viga principal.

- Posição do
equipamento no pátio.
Cada degrau
representa avanço.

O Gráfico 4 apresenta os resultados obtidos após a melhoria realizada, a qual consiste em determinar o set point de corrente variável de acordo com a posição relativa do carro móvel sobre a viga principal do equipamento.

O set point da corrente, que antes era constante, após a melhoria passa a ser variável, obedecendo a uma curva parabólica, onde nas extremidades o valor é máximo e no centro, mínimo. 

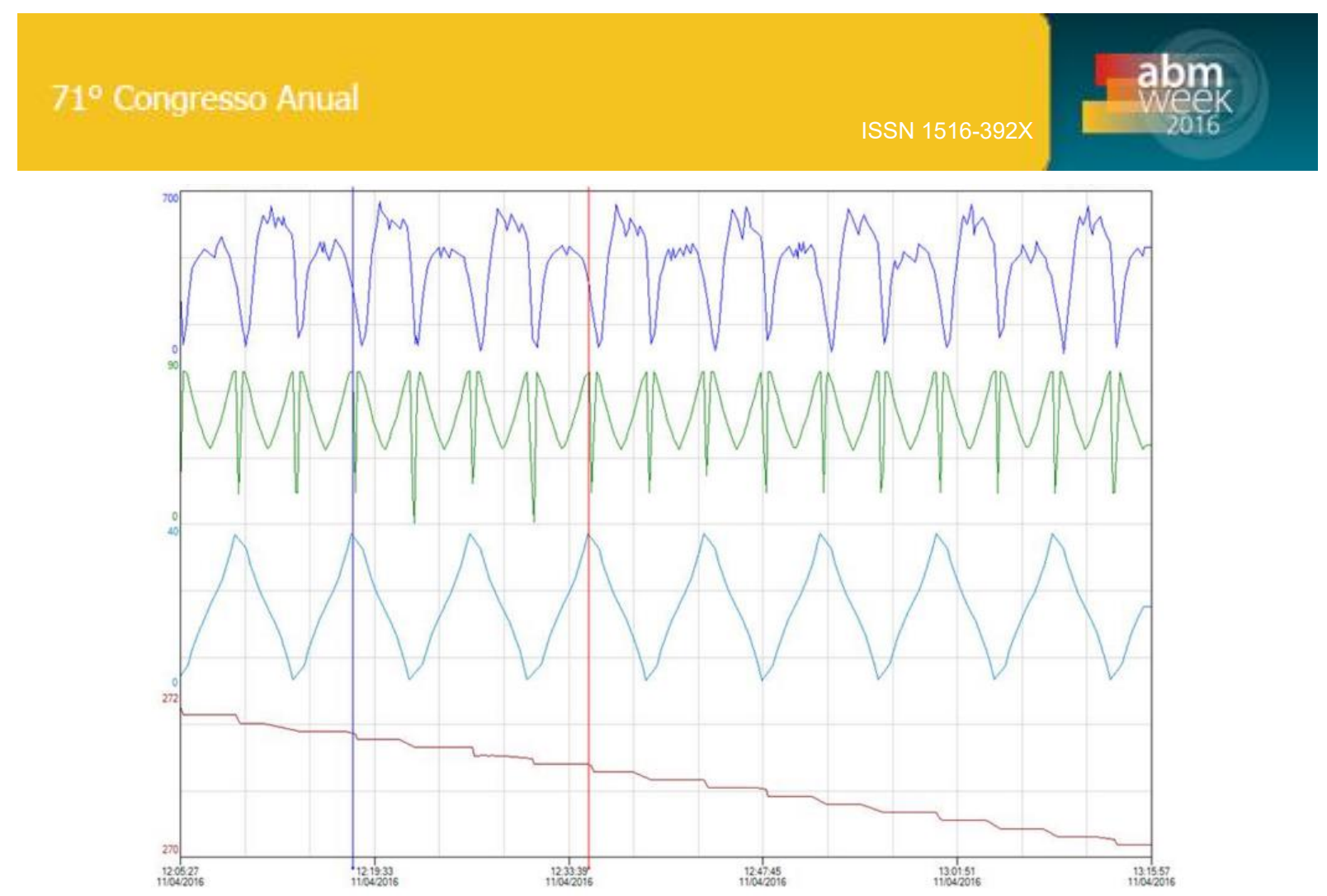

Gráfico 4: Controle de avanço - Após a Melhoria.

Com a implantação desta melhoria foi possível diminuir o range da taxa instantânea de minério retomado, que antes era de 0 a $1200 \mathrm{t} / \mathrm{h}$ e após passa a ser 0 a $700 \mathrm{t} / \mathrm{h}$ com isso obtém-se uma operação mais estável sobre o equipamento, evitando sobrecarga nos sistemas mecânicos e transbordos de material nas correias transportadoras.

\section{START UP E COMISSIONAMENTO}

Ao término da Montagem foi realizado o desbloqueio do equipamento, iniciados os testes e comissionamento, o qual fora realizado inicialmente sem carga e depois com carga.

O desempenho do equipamento foi acompanhado durante 7 dias.

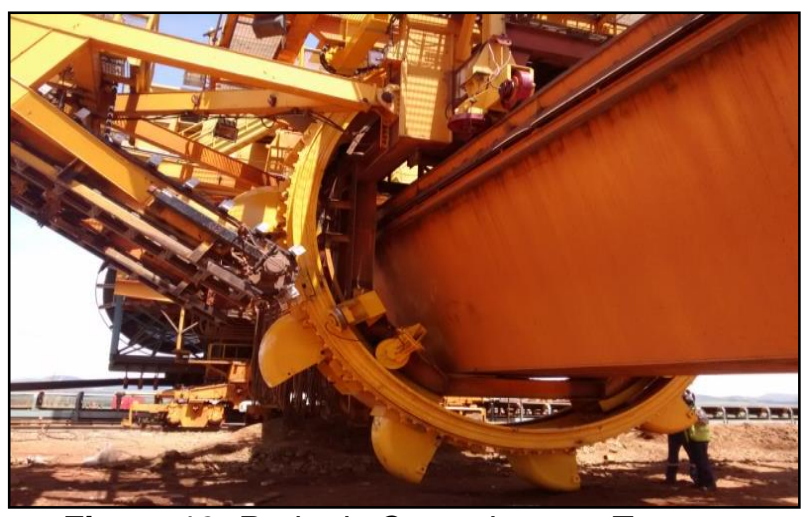

Figura 16: Roda de Caçambas em Testes.

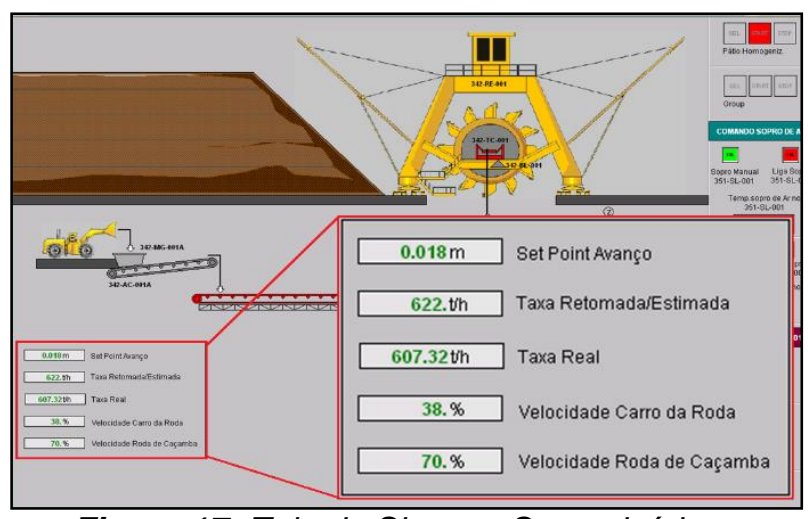

Figura 17: Tela do Sistema Supervisório. 


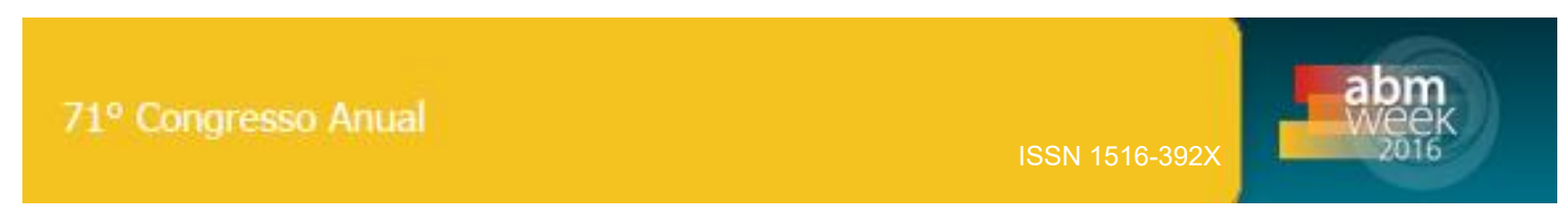

\section{CONCLUSÃo}

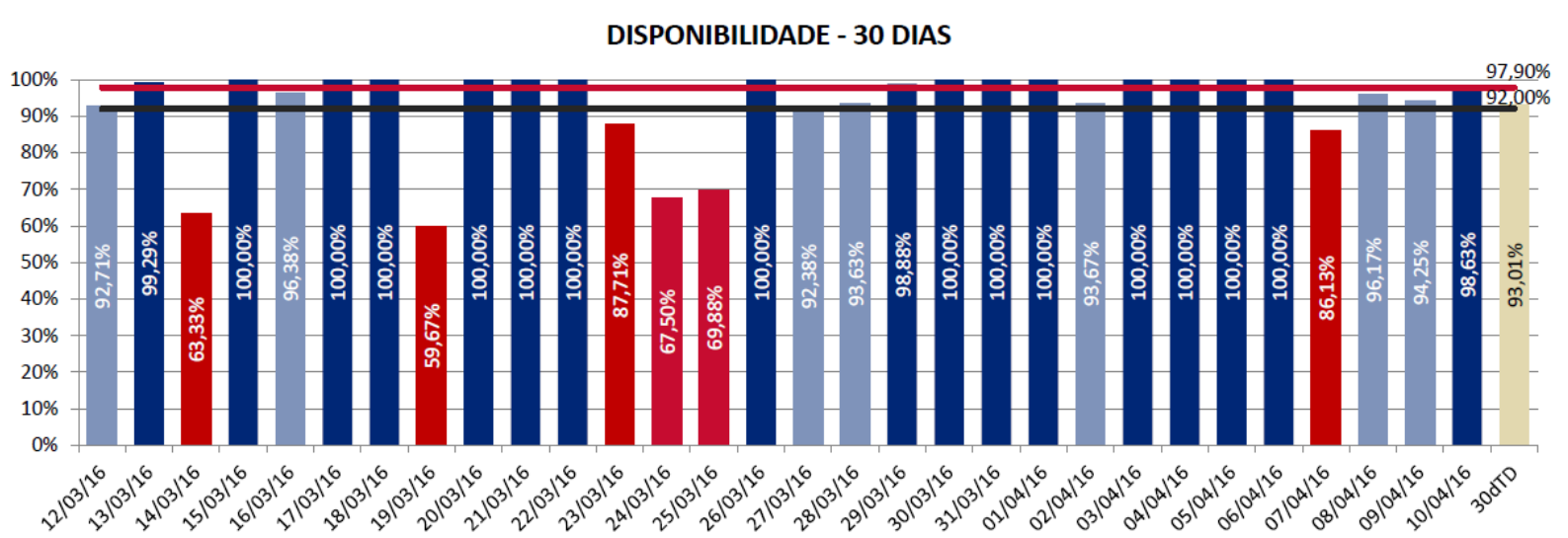

Gráfico 5: Disponibilidade da Retomadora de Minério 342-RE-001.

Após três meses de acompanhamento diário do funcionamento do equipamento pode-se concluir através do Gráfico 5 da Disponibilidade Física que o objetivo do projeto foi alcançado com sucesso, onde o observa-se uma estabilidade na operação do equipamento. Nos pontos onde houve impactos na DF pode-se observar que ocorreram em subsistemas que não estavam diretamente ligados aos sistemas reformados, ou ainda, devido a manutenções preventivas no equipamento.

A Figura 18 mostra a equipe de Engenharia e de Manutenção que trabalho em conjunto para definição de atividades e realização da obra em campo.

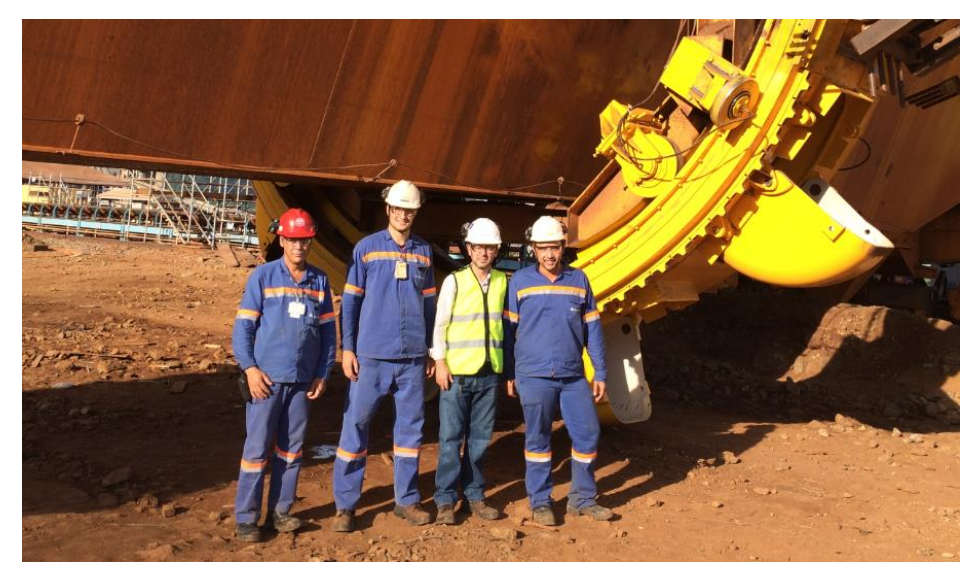

Figura 18: Equipe de Projeto ao final da obra - Dezembro/2015.

\section{REFERÊNCIAS}

$1 \quad$ Flsmidth A/S. "Stacker and reclaimer systems for cement plants." One Source, 2013: 116.

2 ASTM D4356 Standard Practice for Establishing Consistent Test Method Tolerances

3 S. Bošnjak, N. Zrnić, A. Simonović, D. Momčilović, Failure analysis of the end eye connection of the bucket wheel excavator portal tie-rod support. Eng. Fail. Anal. 16, 740-750 (2009).

$4 \quad$ M. Arsić, S. Bošnjak, N. Zrnić, A. Sedmak, N. Gnjatović, Bucket wheel failure caused by residual stresses in welded joints. Eng. Fail. Anal. 18, 700-712 (2011).

5 Robinson G.K., "How much would a blending stockpile reduce variation?" Chemometrics and Intelligent Laboratory Systems, 74 (2004) 121-133 .

6 "The Inventors of Six Sigma". Archived from the original on 2005-11-06. Retrieved 2006-01-29. 